\title{
FRAMEWORK ITIL V3 DOMAIN SERVICE OPERATION DALAM ANALISIS PENGELOLAAN TEKNOLOGI BLENDED LEARNING
}

\author{
Shofwan Hanief ${ }^{1)}$ I Wayan Jefriana ${ }^{2)}$ \\ Program Studi Sistem Informasi, STMIK STIKOM Bali, Denpasar ${ }^{1)}{ }^{2)}$ \\ hanief@stikom-bali.ac.id ${ }^{1)}$ jefriana@stikom-bali.ac.id ${ }^{2)}$
}

\begin{abstract}
Implementation of Information Technology is growing rapidly gives a big impact on the use of information systems / information technology and services of information systems / information technology, so most companies use technology in support of daily operations, so it is necessary to formulate management strategies against information systems / good information technology based on the purpose of the institution or organization that run it to minimize obstacles, improve service quality, and achieve corporate goals. STIKOM Bali is a college institution which is currently studying in the cluster of Information and Communication Technology (ICT). This college is one of the highly dynamic universities with the development of the technology side can follow the times. The learning process that is done at this time in accordance with the instructions of the minister of riser, technology and higher education (Menristekdikti) can not only be done by conventional model but also can be blended learning model. One of the subjects that is currently doing the learning process with blended learning is Introduction to Information Technology, where the course is done in 5 parallel classes and using blended learning model with information system media and kominikasi which have been prepared beforehand by cooperating with centrastudia, a company that focuses on the development of elearning and multimedia systems. In this research, governance analysis will be conducted by focusing on service operation which refers to ITIL framework (Information Technology Infrastructure Library) version 3. The result of this analysis will identify the extent of service operation on blended learning model that applied to Introduction to Information Technology course, and resulted in a management recommendation that can refer to ITIL V3 best practice framework
\end{abstract}

Keywords : information technology, blended learning, governance, ITIL Version 3

ABSTRAK
Cepatnya perkembangan dan penerapan teknologi informasi memberikan dampak besar bagi penggunaan sistem informasi / teknologi informasi dan pelayanan dari sistem informasi/teknologi informasi tersebut, sehingga sebagian besar perusahaan banyak memanfaatkan teknologi dalam mendukung kegiatan operasionalnya sehari-hari dan perlu menyusun strategi pengelolaan terhadap sistem informasi/teknologi informasi yang baik berdasarkan tujuan dari lembaga atau organisasi yang menjalankannya untuk meminimalisasi kendala, meningkatkan kualitas pelayanan, dan mencapai tujuan perusahaan. STIKOM Bali merupakan sebuah lembaga perguruan tinggi yang saat ini program studinya masuk dalam rumpun Teknologi Informasi dan Komunikasi (TIK). Perguruan tinggi ini merupakan salah satu perguruan tinggi yang sangat dinamis dengan perkembangan dari sisi teknologi pun dapat mengikuti perkembangan zaman. Proses pembelajaran yang dilakukan pada saat ini sesuai dengan instruksi mentri riser, teknologi dan pendidikan tinggi (Menristekdikti) tidak hanya dapat dilakukan dengan model konvensional saja namun juga bisa dengan model blended learning. Salah satu mata kuliah yang saat ini dilakukan proses pembelajarannya dengan blended learning adalah Pengantar Teknologi Informasi, dimana matakuliah ini dilakukan di 5 kelas paralalel dan menggunakan model blended learning dengan media sistem informasi dan kominikasi yang telah disiapkan sebelumnya dengan bekerjasama dengan sentrastudia, sebuah perusahaan yang berfokus pada pengembangan sistem-sitem elearning dan multimedia. Dalam penelitian ini akan dilakukan analisis tatakelola dengan memfokuskan pada service operation yang mengacu pada framework ITIL (Information Technology Infrastructure Library) versi 3. Hasil dari analisis ini akan mengidentifikasi sejauh mana service operation pada model pembelajaran blended learning yang diterapkan pada matakuliah Pengantar Teknologi Informasi, dan dihasilkan sebuah rekomendasi pengelolaan yang dapat mengacu pada best practice framework ITIL V3

Kata kunci : teknologi informasi, blended learning, tatakelola, ITIL Versi3 


\section{PENDAHULUAN}

Penerapan teknologi informasi yang terus berkembang dengan sangat cepat memberikan dampak besar bagi penggunaan sistem informasi / teknologi informasi dan pelayanan dari sistem informasi/teknologi informasi tersebut, sehingga sebagian besar perusahaan banyak memanfaatkan teknologi dalam mendukung kegiatan operasionalnya seharihari, sehingga dirasa perlu menyusun strategi pengelolaan terhadap sistem informasi/teknologi informasi yang baik berdasarkan tujuan dari lembaga atau organisasi yang menjalankannya untuk meminimalisasi kendala, meningkatkan kualitas pelayanan, dan mencapai tujuan perusahaan.

STIKOM Bali merupakan sebuah lembaga perguruan tinggi yang saat ini program studinya masuk dalam rumpun Teknologi Informasi dan Komunikasi (TIK). Perguruan tinggi ini merupakan salah satu perguruan tinggi yang sangat dinamis dengan perkembangan dari sisi teknologi pun dapat mengikuti perkembangan zaman.

Proses pembelajaran yang dilakukan pada saat ini sesuai dengan instruksi Mentri riset teknologi dan pendidikan tinggi (Menristekdikti) tidak hanya dapat dilakukan dengan model konvensional saja namun juga bisa dengan model blended learning. Salah satu mata kuliah yang saat ini dilakukan proses pembelajarannya dengan blended learning adalah Pengantar Teknologi Informasi, dimana matakuliah ini dilakukan di 5 kelas paralalel dan menggunakan model blended learning dengan media sistem informasi dan komunikasi yang telah disiapkan sebelumnya dengan bekerjasama dengan sentrastudia, sebuah perusahaan yang berfokus pada pengembangan sistem-sitem elearning dan multimedia.

Dalam penelitian ini akan dilakukan analisis tatakelola dengan memfokuskan pada service operation yang mengacu pada framework ITIL (Information Technology Infrastructure Library) versi 3. Hasil dari analisis ini akan mengidentifikasi sejauh mana service operation pada model pembelajaran blended learning yang diterapkan pada matakuliah Pengantar Teknologi Informasi, dan dihasilkan sebuah rekomendasi pengelolaan yang dapat mengacu pada best practice framework ITIL V3

\section{TINJAUAN PUSTAKA}

\section{ITIL FRAMEWORK}

ITIL adalah best practice dari Service Management IT dan menjadi pilihan terpopuler saat ini sebagai framework analyst business seorang/sebuah client untuk defining roadmap bisnis dan infrastruktur IT yang konsisten dan komprehensif, agar bisnis perusahaan (business plan/strategy) sejalan dengan TI dan infrastruktur, kedepan diharapkan dapat mencapai kualitas dukungan layanan TI yang terkelola (IT Service Management Forum) [1]. Beberapa manfaat yang diberikan ITIL yaitu Peningkatan kepuasan pengguna dan pelanggan dengan layanan TI, meningkatkan ketersediaan layanan, langsung mengarah untuk meningkatkan keuntungan bisnis dan pendapatan, penghematan keuangan melalui pengurangan pengerjaan ulang, waktu yang hilang, peningkatan penggunaan manajemen sumber daya, meningkatkan waktu terhadap pasar untuk produk dan jasa baru, meningkatkan pengambilan keputusan dan risiko dioptimalkan.

ITIL dibangun dalam lima komponen utama dalam ITIL Service Lifecycle yang bisa dilihat pada Gambar 1.

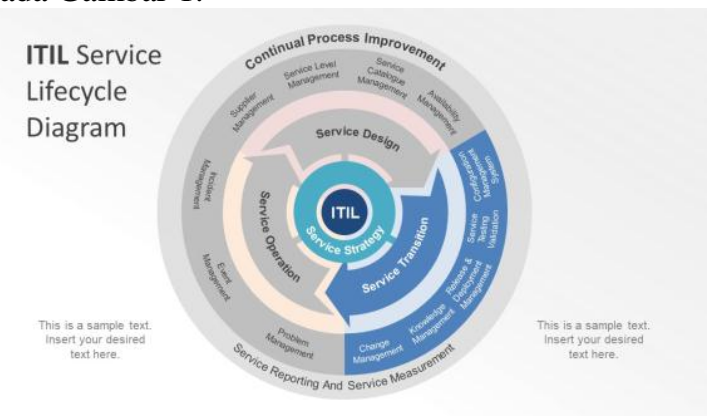

Gambar 1. ITIL Service Lifecycle

Berikut adalah penjelasan lima komponen yang ada yaitu:

- Service Strategy, memberikan panduan implementasi ITSM pada bagaimana memandang konsep ITSM bukan hanya sebagai sebuah kemampuan organisasi (memberikan, mengelola serta mengoperasikan layanan TI), tetapi juga sebagai sebuah asset strategis perusahaan. Panduan ini disajikan dalam bentuk prinsip-prinsi dasar dari konsep ITSM, acuan-acuan serta proses-proses inti yang beroperasi di keseluruhan tahapan ITIL Service Lifecycle.

- Service Design, member panduan kepada organisasi TI secara sistematis 
dan best practice mendesain serta membangun layanan TI maupun implementasi ITSM itu sendiri. Service Design berisi prinsi-prinsi dan metode desain untuk mengkonversi tujuan strategis organisasi TI dan bisnis menjad portofolio/koleksi layanan TI serta aset-aset layanan seperti server, storage dan sebagainya. Ruang lingkup Service Design tidak hanya mendesain layanan TI baru, namun juga prosesproses perubahan maupun peningkatan kualitas layanan, kontinyuitas layanan maupun kinerja dari layanan.

- Service Transition, menyediakan panduan kepada organisasi TI untuk dapat mengembangkan kemampuan untuk mengubah hasil desain layanan TI baik yang baru maupun layanan TI yang diubah spesifikasinya ke dalam lingkungan baru maupun layanan TI yang diubah spesifikasinya ke dalam lingkungan operasional. Tahapan lifecycle ini memberikan gambaran bagaimana sebubah kebutuhan yang didefinisikan dalam Service Strategy kemudian dibentuk dalam Service Design untuk secara efektif direalisasikan dalam Service Operation.

- Service Operation, merupakan tahapan lifecycle yang mencakup semua kegiatan operasional harian pengelolaan layanan-layanan TI. Di dalamnya terdapat berbagai panduan pada bagaimana mengelola layanan TI secara efisien dan efektif serta menjamin tingkat kinerja yang telah dijanjikan dengan pelanggaran sebelumnya. Panduan-panduan ini mencakup bagaimana menjaga kestabilan operasional layanan TI serta pengelolaan perubahan desain, skala, ruang lingkup serta target kinerja layanan $\mathrm{TI}$.

- Continual Service Improvement, berisi panduan penting dalam menyusun serta memelihara kualitas layanan dari proses desai, transisi dan pengoperasioannya. CSI mengkombinasikan berbagai prinsip dan metode dari manajemen kualitas.

Penelitian yang terkait dengan ITIL diantaranya adalah sebagai berikut. Penelitian pertama yaitu "Analisis Kualitas Layanan Teknologi Informasi dengan Menggunakan Framework Information Technology Infrastructure Library V.3 (ITIL V.3) Domain
Service Transition (Studi Kasus pada Costumer Service Area Telkom Salatiga)" yang mempunyai latar belakang masalah karena adanya sistem baru atau modifikasi sisten yang akan mempengaruhi suatu pelayanan pelanggan sehingga dapat mempengaruhi juga manajemen di dalamnya. Hasil dari penelitian ini yaitu CSA Salatiga menyadari pentingnya masa transisi sebelum releasenya sebuah sistem seperti pergantian sistek SISKA ke I-SISKA agar sistem baru dapa diterima oleh para pegawai sehingga dapat digunakan untuk menanggap keluhan pelanggan dengan beberapa dokumen yang bisa dilengkapi untuk meningkatkan performa perusahaan dalam melayani pelanggan [2].

Penelitian yang kedua yaitu "Analisis Kualitas Layanan TI pada Aplikasi SLiMs menggunakan Framework ITIL V.3 Domain Service Operation (Studi Kasus: Kantor Perpustakaan dan Arsip Daerah Kota Salatiga)" yang mempunyai latar belakang masalah pada layanan TI yang sering muncul selama proses transaksi sistem SLiMs. Penelitian ini menghasilkan output berupa rekomendasi berdasarkan framework ITIL v3 domain service operation. Layanan yang ada pada Kantor Perpustakaan dan Arsip Daerah Kota Salatiga masih memiliki banyak kelemahan seperti human error dan kurangnya SDM [3].

\section{Metode Penelitian}

Penelitian ini merupakan penelitian dengan metode kualitatif dengan pendekatan induktif, dimana permasalahan yang diangkat pada penelitian ini merupakan permasalahan yang terjadi pada sebuah lembaga pendidikan yaitu STIKOM Bali yang berdasarkan fakta lalu dianalisis dan dicarikan pemecahan terhadap permasalahan yang ada yang berupa sebuah rekomendasi dari hasil kesimpulan yang telah diambil. Dalam penelitian ini menggunakan responden beberapa mahasiswa yang tergabung dalam kelas matakuliah PTI dengan model pembelajaran blended yang menjadi objek penelitian, yakni elearning yang dikembangkan oleh perusahaan pihak ketiga yang bekerjasama dengan STIKOM Bali. Adapun tahapan pada penelitian adalah seperti pada gambar 2 .

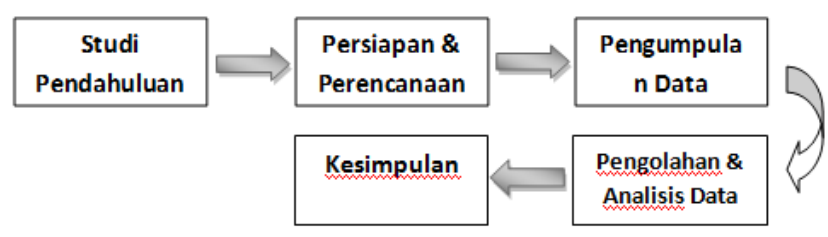

Gambar 2. Metode Penelitian 
- Pada tahap satu yakni melakukan studi literatur dan cari informasi awal. Maksud dari studi literatur di sini yaitu mempelajari kembali literatur ITIL V.3 agar lebih memahami apa yang akan diteliti dan cari informasi awal di mana antara literatur yang dipelajari bisa diterapkan untuk menjawab masalahmasalah yang terjadi pada sistem yang digunakan untuk pembelajaran blended learning. Pendekatan yang dilakukan dengan menggunakan ITIL V.3 domain service operation.

- Persiapan dan Perencanaan Analisis sesuai dengan Domain Service Operation merupakan bagian tahapan rancangan pertanyaan karena penelitian dilakukan dengan cara pengumpulan data secara kualitatif. Pertanyaan yang ada sesuai dengan kebutuhan yang menjawab pada domain Service Operation.

- Pengumpulan data, pada tahap ini peneliti menggunakan beberapa metode penelitian, yaitu wawancara yang akan dilakukan pada para pengajar dan mahasiswa, observasi langsung dimana melihat sendiri kenyataan yang berlangsung di lapangan (objek penelitian) dan dokumen- dokumen yang diperoleh dari objek penelitian.

- Analisis data berdasarkan alat ukur ITIL V.3 hasil temuan berupa bukti pernyataan narasumber saat wawancara serta beberapa bantuan dokumen. Setelah itu hasil tersebut akan dilakukan analisis kualitas layanan tiap proses dalam ITIL V.3 dengan domain service operation lalu diturunkan ke 5 sub domain. Pada proses ini, verifikasi data dilakukan secara terus menerus sepanjang proses penelitian karena penelitian ini merupakan penelitian kualitatif.

- Kesimpulan, pada Tahap ini peneliti membuat dan menyusun temuan serta rekomendasi berdasarkan hasil pengolahan dan analisis data pada proses sebelumnya. Temuan dan rekomdasi disusun berdasarkan standar ITIL V3 domain service operation.

\section{ANALISIS DAN PEMBAHASAN}

\section{TAMPILAN APLIKASI}

Pada saat menjalankan pembelajaran dengan blended leaning maka perlu adanya media teknologi yang digunakan untuk melakukan proses pembelajaran. Adapun teknologi yang digunakan untuk mode pembelajaran dengan mode blended learning adalah sebuah aplikasi elearning yang dikembangkan oleh perusahaan yang bekerjasama dengan STIKOM Bali, dimana aplikasi ini dibuat atas dasar pemikiran dari STIKOM Bali dan beberapa kampus TI yang bekerjasama untuk mengembangkan model pembelajaran dengan blended learning. Berikut adalah gambar dari aplikasi elearning yang digunakan sebagai media pembelajarannya.

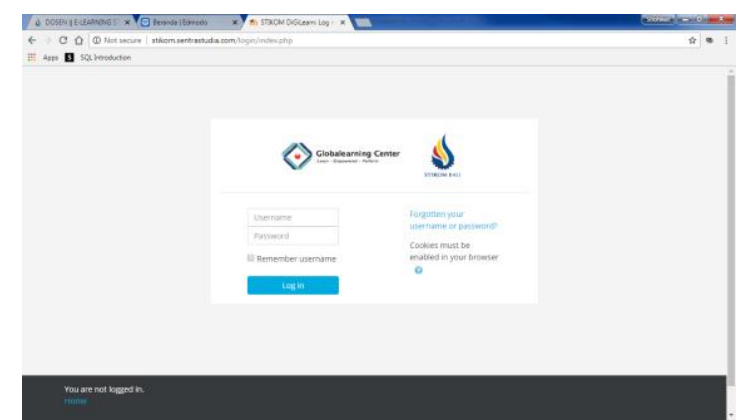

Gambar 3. Tampilan aplikasi elearning

Pada elearning tersebut proses pembelajaran dengan blended learning dilakukan. Adapun mekanisme perkuliahan yang dilakukan pun diatur dan djelaskan pada aplikasi sehingga mahasiswa dan dosen mengetahui mode perkuliahan yang akan berjalan di setiap pertemuan.

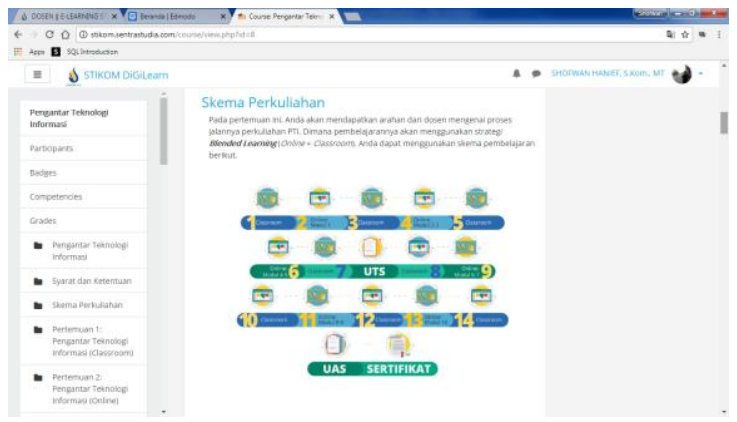

Gambar 4. Mekanisme Perkuliahan

Dalam mekanisme perkuliahan ini dijelaskan kapan perkuliahan dilakukan dengan tatap muka, dan kapan dilakukan dengan media teknologi atau elearning. Pada setiap pertemuan disediakan materi dalam bentuk digital untuk para mahasiswa. Jika pada 
pertemuan sebelumnya mahasiswa belum selesai melakukan pembelajaran (baik itu membaca materi, menjawab soal-soal jika ada dan atau quis) maka tidak bisa mengakses materi untuk pertemuan selanjutnya. Dan pada saat mahasiswa sudah mengakses materi akan terekam pada sistem yang nantinya menjadi acuan untuk absensi kehadiran. Berikut adalah tampilan dari konten di setiap pertemuan.

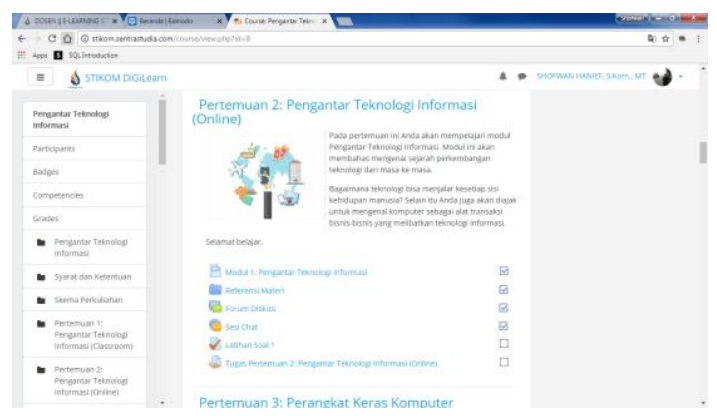

Gambar 5. Tampilan mode perkuliahan online

Pada mode perkuliahan online seperti yang tersaji pada gambar 5 diatas, terdapat matei yang berupa video animasi dan beberapa fasilitas lainnya seperti tugas, forum diskusi, chatt, dan lainya. Apabila semua nya sudah tercentang maka perkuliahan dinyatakan selesai untuk topic atau pertemuan ini, dan absensi mahasiswa akan terekam pada sistem, sekaligus juga membuka fasilitas pertemuan online selanjutnya. Berikut pada gambar 6 adalah contoh tampilan materi yang berupa multimedia dengan video animasi.

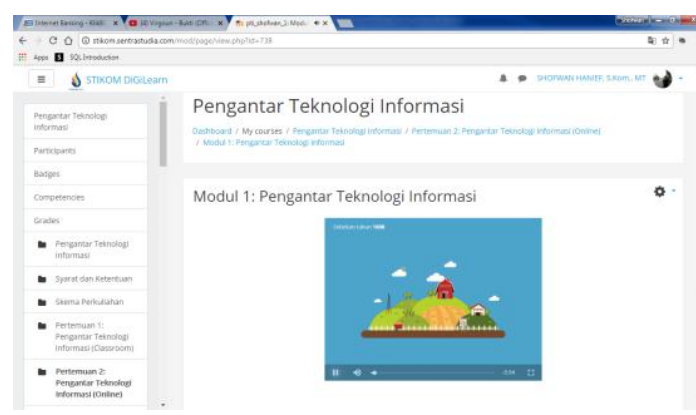

Gambar 6. Materi konten pembelajaran

Dari beberapa fasilitas yang ada pada elearning tersebut, masih ada beberapa fasilitas yang berfungsi tidak hanya sebagai proses belajar-mengajar, namun juga tersedia fasilitas beberapa laporan yang dapat menjadi bahan untuk dosen pengampu matakuliah seperti laporan absensi, nilai tugas, keaktifan mahasiswa pada forum, dan yang lainnya. Ketersediaan media teknologi ini pun tak lepas dari layana yang ada pada sistem yang digunakan. Baik itu berupa layanan dari hasil proses yang dilakukan di sistem, ataupun layanan support dari pihak pengembang terkait error system, bug, dan kesalahan lainnya yang bersifat prosedural maupun non prosedural.

\section{SKEMA PERKULIAHAN DENGAN BLENDED LEARNING}

Perkuliahan dengan model blended learning merupakan sebuah model perkuliahan yang mengkombinasikan antara model perkuliahan konvensional dan media teknologi. Agar mutu dan keluaran peserta dalam hal ini mahasiswa yang mengikuti perkuliahan blendec learning tidak mempunyai gap yang sangat besar, maka dibuatlah mekanisme perkuliahan yang wajib difahami oleh para perserta atau mahasiswa dan para dosen pengampu matakuliah, dalam hal ini sebagai pilot project adalah amta kuliah pengantar teknologi informasi. Adapun skema yang dibuat adalah seperti gambar berikut.

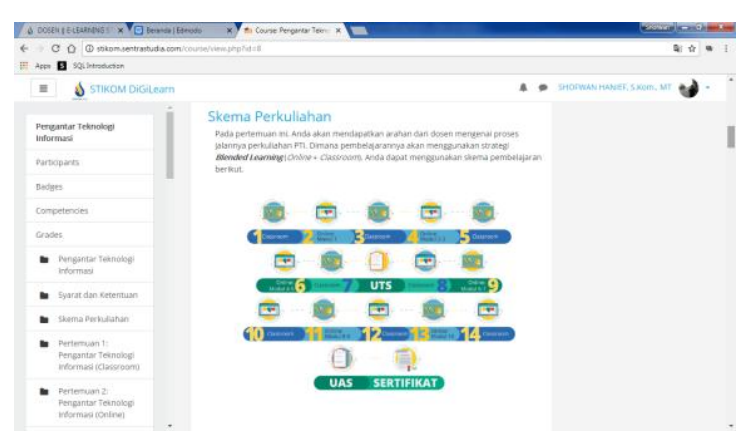

Gambar 7. Mekanisme perkuliahan blended learning

\section{ANALISA DENGAN FRAMEWORK ITIL V3}

Pada penelitian ini dilakukan penelitian dengan mengacu pada framework ITIL V3, sejauh mana pengelolaan aplikasi pada pembelajaran dengan model blended learning pada domain service operation dengan tujuan memberikan guide untuk manajemen layanan TI.

\section{Domain SERVICE OPERATION EVENT MANAGEMENT}

Event management adalah perubahan suatu kondisi yang memiliki makna bagi pengelolaan item konfigurasi pada layanan TI[4]. Pada proses ini akan mendeteksi pemberitahuan, sementara pemantauan memeriksa status suatu komponen bahkan ketika tidak ada peristiwa terjadi. Tujuan event management untuk mendeteksi event dan memutuskan pendekatan apa saja yang perlu dilakukan untuk event tersebut[5]. 
Berdasarkan kebutuhan dari koneksi internet pada sistem yang digunakan pada aplikasi yang digunakan dan melakukan wawancara dengan bagian sistem dan jaringan di STIKOM Bali, ternyata ada aplikasi yang dapat digunakan untuk memonitor bandwith yang digunakan untuk elearning yang digunakan. Berdasarkan hal tersebut diketahui bahwa STIKOM Bali sudah menerapkan sistem untuk proses monitoring pada operasi layanan.

\section{DOMAIN SERVICE OPERATION INCIDENT MANAGEMENT}

Incident management merupakan gangguan yang tidak direncanakan pada layanan TI, atau penurunan kualitas TI [2]. Suatu pengelolaan atas insiden yang dapat terjadi secara tiba-tiba, mulai dari kemana harus melaporkan ketika terjadi insiden hingga bagaimana penanggulangan untuk menimalisis efek dari kejadian. Tujuannya adalah bagaimana mengembalikan operasional secara cepat agar tidak mengganggu terjadi proses pembelajaran pada saat menggunakan media elearning.

Kejadian yang menyebabkan terjadinya kondisi tidak normal biasanya terjadi oleh mahasiswa dan dosen sebagai pengguna dari sistem. Berdasarkan proses pembelajaran yang sudah dilakukan.

\section{DOMAIN SERVICE OPERATION REQUEST FULFILMENT}

Request fulfilment merupakan kondisi dari permintaan pengguna untuk dapat melakukan request untuk mengembangkan layanan, informasi, saran untuk perubahan standar, atau untuk akses ke layanan TI yang perlu ditata[2]. Tujuan dari request fulfilment adalah untuk standarisasi pengguna dalam melakukan penerimaan dan menerima layanan terkait dengan pelaksanaan pembelajaran blended learning dengan menggunakan media elearning.

Berdasarkan hal tersebut didapatkan hasil bahwa dalam melakukana request pada elearning pengguna dibatasi hanya pada pengguna dosen saja, untuk mahsiswa dikoordinir oleh masing-masing dosen pengampu di kelas masing-masing dengan tujuan agar terkontrol dan terdefinisi dengan jelas permintaan atau perubahan yang diminta kepada fihak vendor atau pengembang aplikasi.

\section{Domain SERVice Operation Problem MANAGEMENT}

Problem management disini merupakan suatu kondisi yang menyebabkan suatu insiden atau beberapa insiden akibat penggunaan oleh user [2]. Tujuan dari problem management adalah untuk meminimalisasi atau mencegah adanya suatu insiden dan akibat yang ditimbulkannya, sehingga insiden yang terjadi tidak berulang-ulang dan dapat ditangani dengan baik [2].

Sebagai contoh insiden yang sering terjadi pada perkuliahan dengan blended learning ini adalah lost connections atau network error. Insiden ini berpotensi untuk terjadi berulangulang sehingga harus ada penangulangan yang cepat ketika terjadi insiden tersebut pada saat perkuliahan menggunakan teknologi informasi. Masalah tersebut sudah diketahui oleh pengelola sistem jaringan di STIKOM Bali, namun belum dapat dilakukan.

\section{DOMAIN SERVICE OPERATION ACCESS MANAGEMENT}

$\checkmark$ Access management merupakan pemberian kewenangan atau otorisasi kepada pengguna agar dapat menggunakan layana $\mathrm{n}$ pada sistem yang digunakan[2]. Tujuannya agar para pengguna teratur dalam menggunakan layanan atau kelompok layanan dan mencegah akses kepada pengguna yang tidak berwenang.

Sebagai contoh pada elearning ini adalah pengaturan akses antara dosen dan mahasiswa. Ketika ada mahasiswa ada yang belum mengumpulkan tugas via elearning, dapat melakukan permohonan kepada dosen agar dapat dibukakan kembali akse agar mahasiswa dapat mengumpulkan tugas. Sehingga jelas pada sistem ini layanan-layanan apa saja yang dapat diakses oleh mahasiswa atau dosen.

Dari hasil analisis menggunakan framework ITIL V3 domain service management, ada beberapa hal terkait subdomain yang telah dilakukan analisis. Beberapa hasil analisis menunjukan bahwa sudah cukup baik dan ada beberapa hal yang direkomendasikan agar dapat meningkat sehingga layanan dapat dilakukan lebih baik lagi. Adapun hasil analisi tersaji dalam table berikut. 


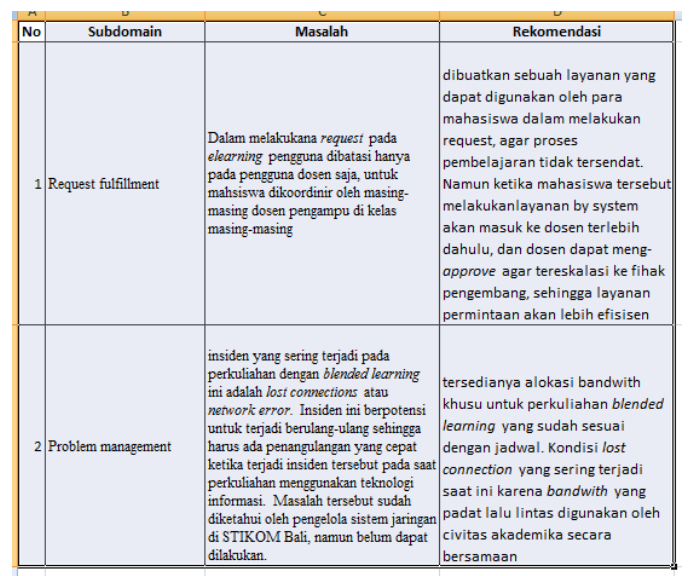

Tabel 1. Rekomendasi hasil analisis

\section{KESIMPULAN}

Blended learning yang diterapkan pada mata kuliah PTI di STIKOM Bali yang menggunakan teknologi informasi manggunakan media elearning secara umum telah berjalan dan sesuai dengan proses service operation pada salah satu domain framework ITIL V3. Atas dasar hasil analisis yang telah dilakukan terhadap manajemen layanan TI disimpulkan bahwa proses layanan kinerja pada sistem elearning sudah cukup baik, berdasarkan penilaian terhadap sistem itu sendiri dan wawancara dengan responden yaitu beberapa mahasiswa dan dosen pengguna elearning ini, walaupun pada beberapa sub domain masih terdapat beberapa masalah yang telah dijelaskan.

\section{DAFTAR PUSTAKA}

[1] IT Service Management Forum, An Introductory Overview of ITIL V.3.

[2] Kurniawati, Ria., dan Manuputty, A.D. 2013. "Analisis Kualitas Layanan Teknologi Informasi dengan Menggunakan Framework Information Technology Infrastructure Library V.3 (ITIL V.3) Domain Service Transition (Studi Kasus pada Costumer Service Area Telkom Salatiga)”. Skripsi, Salatiga : Jurusan Sistem Informasi Universitas Kristen Satya Wacana.

[3] Junginger, Aprila. et al. 2016. "Analisis Kualitas Layanan TI pada Aplikasi SliMs Menggunakan Framework ITIL V.3 Domain Service Operation (Studi Kasus : Kantor Perpustakaan dan Arsip Daerah Kota Salatiga).
[4] Cahyaningtyas, AR. Anggun. et al. 2012. "Audit Sistem Informasi dengan ITIL Version 3 Sub Domain Service Desk, Incident Management, dan Problem Management di Bidang Keuangan Dishubkombudpar Kota Salatiga”. Skripsi, Salatiga : Jurusan Sistem Informasi Universitas Kristen Sayta Wacana.

[5] Caroline, Yoan., dan Manuputty, A.D. 2015. "Analisis Kualitas Layanan TI Menggunakan ITIL V.3 (Studi Kasus: Keuangan Group PT. Pura Barutama”. Skripsi, Salatiga : Universitas Kristen Satya Wacana. 